\title{
Pengaruh Kemampuan Berpikir Kritis Siswa yang Diajarkan dengan Model Pembelajaran Example Non Example di SMP Negeri 1 NA. IX-X pada Tahun Ajaran 2017/2018
}

\section{The Influence of Student Critical Thinking Ability That Is Teached with Example Non Example Learning Models in The Subject Class VII of SMP Negeri 1 NA. IX-X 2017/2018 Learning Year}

\author{
Irmayanti \\ Program Studi Pendidikan Matematika, STKIP Labuhan Batu \\ Jalan Sisingamangaraja No. 126A, KM, 3,5 Aek Tapa Rantauprapat email: irmayantiritonga2@gmail.com
}

\begin{abstract}
Abstrak
Tujuan dari penelitian ini adalah untuk mengetahui: 1) Pengaruh model pembelajaran example non example terhadap kemampuan berpikir kritis siswa-siswi kelas VII SMP Negeri $1 \mathrm{Na}$. IX-X, 2) Pola jawaban siswa melalaui model pembelajaran example non example. Jenis penelitian ini adalah kuantitatif dan tempat penulis mengadakan penelitian adalah SMP Negeri $1 \mathrm{Na}$. IX-X dikelas VII Tahun Pembelajaran 2017/2018. Populasi dalam penelitian ini adalah seluruh kelas VII yang berjumlah 320 siswa. Sampel dalam penelitian ini kelas $\mathrm{VII}_{9}$ sebanyak 32 orang sebagai kelas eksperimen dan kelas $\mathrm{VII}_{8}$ sebanyak 32 orang sebagai kelas kontrol. Teknik pengumpulan data diperoleh dengan cara tes berupa uraian dan teknik analisis data yang digunakan adalah, uji normalitas, uji homogenitas, uji hipotesis atau uji t. Berdasarkan hasil tes yang diberikan rata-rata nilai pretest siswa adalah 8.56, dan standar deviasi 1.134. Rata-rata nilai posttest siswa adalah 10.96, dan standar deviasi 3.128 hal ini menunjukkan bahwa kemampuan berpikir kritis siswa meningkat setelah diberikan perlakuan (model pembelajaran example non example). Berdasarkan pengujian hipotesis menggunakan uji t dengan teknik paired samples $t$-test ditunjukkan bahwa kelas eksperimen pada taraf signifikan $\alpha=0.05$ dalam kasus ini thitung yaitu -9.210 dan tabel $=1.695$, sehingga dalam hal ini thitung $<t_{\text {tabel }}$ yang artinya $\mathrm{H}_{0}$ ditolak $\mathrm{H}_{1}$ diterima berarti ada pengaruh model pembelajaran example non example terhadap kemampuan berpikir kritis matematika siswa. Berdasarkan hasil penelitian bahwa semakin sering guru menggunakan model example non example dalam pembelajaran Matematika, maka kemampuan berpikir kritis siswa akan semakin meningkat
\end{abstract}

Kata Kunci: Model Pembelajaran Example Non Example, Kemampuan Berpikir Kritis Siswa.

\begin{abstract}
The purpose of this study is to find out: 1) The effect of example non example learning models on the critical thinking skills of grade VII students of SMP Negeri $1 \mathrm{Na}$. IX-X, 2) The pattern of student answers through the example non example learning model. This type of research is quantitative and the place where the authors conducted research is SMP Negeri 1 Na. IX-X in class VII 2017/2018 Academic Year. The population in this study was all VII classes, amounting to 320 students. The sample in this study class VII9 as many as 32 people as the experimental class and class VII8 as many as 32 people as the control class. Data collection techniques were obtained by means of a test in the form of a description and data analysis techniques used were, normality test, homogeneity test, hypothesis test or $t$ test. Based on the test results given the average pretest score of students is 8.56, and the standard deviation is 1.134. The average posttest score of students is 10.96, and the standard deviation of 3.128 shows that the critical thinking ability of students increases after being given treatment (example non example learning model). Based on testing the hypothesis using the $t$ test with paired samples $t$-test technique showed that the experimental class at a significant level $\alpha=0.05$ in this case tcount is $-9,210$ and ttable $=1,695$, so in this case tcount $<$ ttable which means $\mathrm{HO}$ is rejected $\mathrm{H} 1$ is accepted means there is the influence of the example non example learning model on students' mathematical critical thinking skills. Based on the results of research that the more often teachers use the model example non example in learning mathematics, the critical thinking ability of students will increase
\end{abstract}

Key Words : Example Non Example Example Learning Model, Students' Critical Thinking Ability 


\section{Pendahuluan}

Model mengajar pada dasarnya merupakan bentuk pembelajaran yang tergambar dari awal sampai akhir yang disajikan secara khas oleh guru. Perlu diketahui bahwa baik atau tidaknya suatu pemilihan model pembelajaran akan tergantung tujuan pembelajarannya, kesesuain dengan materi pembelajaran, tingkat perkembangan siswa, kemampuan guru dalam mengelolah pembelajaran serta mengoptimalkan sumbersumber belajar yang ada.

Berdasarkan hasil observasi dan wawancara peneliti dengan salah satu guru matematika di SMP Negeri $1 \mathrm{Na}$. IX-X yang bernama Lasmaria Sibarani, S.Pd, beliau mengatakan bahwa pembelajaran yang digunakan adalah pembelajaran konvensional yang berpusat pada guru dengan metode ceramah. Selain itu beliau mengatakan bahwa pembelajaran yang telah diberikan sebelumnya ketika keesokan harinya ditanyakan siswa sudah lupa. Guru tersebut pernah mencoba metode lain dalam pembelajaran namun siswa menolak untuk melakukan pembelajaran tersebut, dengan terpaksa guru melakukan cara konvensional.

Persepsi mengenai pelajaran matematika, siswa menganggap bahwa matematika sulit dan tidak mudah dipahami. Mata pelajaran matematika merupakan ilmu yang cenderung menitik beratkan pada penguasaan rumus sehingga membuat siswa menjadi pasif dan tidak termotivasi untuk berpikir dan berkreativitas. Materi matematika yang kebanyakan berhitung membuat siswa merasa pusing, dan tidak menyukai pelajaran matematika.

Dengan memusatkan perhatian siswa terhadap example non example, diharapkan akan dapat mendorong siswa untuk menuju pemahaman yang lebih baik dalam mengenai materi yang ada[1]. Penerapan model pembelajaran example non example ini dirancang agar siswa memiliki kompetensi dalam menganalisis gambar serta memberikan diskripsi mengenai apa yang ada didalam gambar dan diharapkan dapat membantu siswa untuk lebih mudah memahami materi pelajaran matematika sehingga kemampuan berpikir kritis siswa lebih baik.

\section{Metode Penelitian}

Pembelajaran Example Non Example adalah salah satu contoh model pembelajaran yang menggunakan media[3]. Media dalam pembelajaran merupakan sumber yang digunakan dalam proses belajar mengajar. Model pembelajaran Example Non Example atau juga biasa disebut Examples and Non-Examples merupakan model pembelajaran yang menggunakan gambar sebagai media pembelajaran. Penggunaan media gambar ini disusun dan dirancang agar anak dapat menganalisis gambar tersebut menjadi sebuah bentuk diskripsi singkat mengenai apa yang ada didalam gambar[5].

Example non example adalah taktik yang dapat digunakan untuk mengajarkan definisi konsep. Adapun strategi yang bisa digunakan bertujuan untuk mempersiapkan siswa secara cepat dengan menggunakan dua hal yang terdiri dari example dan non example dari suatu definisi konsep yang ada, dan meminta siswa untuk mengklasifikasikan keduanya sesuai dengan konsep yang ada. Example memberikan gambaran akan sesuatu yang menjadi contoh dalam materi yang sedang dibahas, sedangkan non-example memberikan gambaran akan sesuatu yang bukanlah contoh dari suatu materi yang sedang dibahas.

Langkah-langkah [2] model pembelajaran example non example diantaranya : Guru mempersiapkan gambar-gambar sesuai dengan tujuan pembelajaran, Guru menempelkan gambar dipapan tulis atau ditayangkan melalui LCD atau OHP, atau dapat pula menggunakan proyektor, Guru memberi petunjuk dan memberi kesempatan kepada siswa untuk memperhatikan/menganalisis gambar, Melalui diskusi kelompok 3-4 orang siswa, hasil diskusi dan analisis gambar tersebut dicacat pada kertas kerja siswa, Tiap kelompok diberi kesempatan membacakan hasil diskusinya, Setelah memahami hasil dari analisis yang dilakukan siswa, guru mulai menjelaskan materi sesuai tujuan pembelajaran yang ingin dicapai, Guru dan siswa menyimpulkan materi sesuai dengan tujuan pembelajaran.

Kemampuan menurut Kamus Besar Bahasa Indonesia berasal dari kata "mampu" yang berarti kuasa, dapat, dan sanggup melakukan sesuatu. Selain itu kemampuan adalah sebagai daya, kapabilitas, kapasitas, kebiasaan, kecakapan, kompetensi, keahlian, kelebihan, kemahiran, keterampilan, penguasaan. Berpikir kritis memungkinkan siswa untuk menemukan kebenaran ditengah banyaknya kejadian dan informasi dalam kehidupan sehari-hari[6]. Berpikir kritis adalah sebuah proses sistematis yang memungkinkan siswa untuk merumuskan dan mengevaluasi keyakinan dan pendapat mereka sendiri.

Berpikir kritis merupakan sebuah proses terorganisasi yang memungkinkan siswa mengevaluasi bukti, asumsi, logika, dan bahasa yang mendasari pernyataan orang lain[7]. Berpikir kritis adalah berpikir logis dan reflektif yang difokuskan pada pengambilan keputusan yang akan dipercayai atau dilakukan[4]. Ketika seseorang memiliki kemampuan berpikir kritis maka secara otomatis seseorang tersebut dapat bertahan dalam menyelesaikan permasalahan. Berpikir kritis penting bagi siswa karena dengan berpikir kritis siswa dapat 
menganalisis dan mencari solusi serta membuat keputusan terhadap suatu masalah secara sistematis khususnya dalam pembelajaran[4].

Kemampuan berpikir kritis dibagi menjadi 5 [4] yaitu : (1) basic clarification (memberikan penjelasan dasar), (2) the bases for the decision (memberikan alasan untuk suatu keputusan), (3) inference (menyimpulkan), (4) advanced clarification (memberikan penjelsan lanjut), (5) supposition and integration (dugaan dan keterpaduan). Pada penelitian ini, penulis mengambil 3 aspek kemampuan berpikir kritis yaitu:

1. Memberikan penjelasan dasar (basic clarification)

2. Menyimpulkan (inference)

3. Memberikan penjelasan lanjut (advanced clarification)

Desain yang digunakan dalam penelitian ini adalah desain pretes postes tak ekuivalen. Desain ini hampir sama dengan pretest-posttest control group design, hanya pada desain pretest-posttest non equivalent ini kelompok eksperimen maupun kontrol tidak dipilih secara random. Dalam penelitian ini adalah seluruh kelas VII yaitu VII 1 sampai $\mathrm{VII}_{10}$ SMP Negeri $1 \mathrm{Na}$. IX-X Tahun Ajaran 2017/2018. Sampel yang akan diambil dalam penelitian ini yaitu kelas $\mathrm{VIl}_{9}$ terpilih sebagai kelas eksperimen dan kelas $\mathrm{VII}_{8}$ sebagai kelas kontrol. Instrumen dalam penelitian ini menggunakan teknis tes yaitu tes kemampuan berpikir kritis berupa uraian sebanyak 10 soal.

Dalam penelitian kuantitatif, analisis data merupakan kegiatan setelah data dari seluruh responden atau sumber data lain terkumpul. Kegiatan analisis data adalah mengelompokkan data berdasarkan variabel dan jenis responden, mentabulasi data berdasarkan variabel dari seluruh responden, menyajikan data tiap variabel yang diteliti, melakukan perhitungan untuk hipotesis yang telah diajukan[8]. Untuk melakukan analisis data guna mengkaji hipotesis dilakukan langkah-langkah sebagai berikut: Uji normalitas, Uji homogenitas dan uji $t$ test (Paired Samples T.Test).

\section{Hasil Penelitian dan Pembahasan}

\section{Hasil Penelitian}

Berdasarkan data yang diperoleh dari nilai pretest dan posttest, maka diperoleh hasil uji normalitas seperti tabel dibawah ini:

Tabel 1. Rekapitulasi Hasil Perhitungan Uji Normalitas di Kelas Eksperimen

\begin{tabular}{|l|l|l|l|c|}
\hline Data & Kelas & $X_{\text {hitung }}$ & $X_{\text {tabel }}$ & $\begin{array}{c}\text { Kesimpulan } \\
\text { Pretest }\end{array}$ \\
VIl9 & 0.111 & 1.695 & $\begin{array}{c}\text { Ho diterima } \\
\text { (Normal) }\end{array}$ \\
\hline Posttest & $\mathrm{VIl}_{9}$ & 0.270 & 1.695 & $\begin{array}{c}\text { Ho diterima } \\
\text { (Normal) }\end{array}$ \\
\hline
\end{tabular}

Berdasarkan tabel 1 diatas menunjukkan bahwa data nilai pretest dan posttest kemampuan berpikir kritis siswa yang menggunakan model pembelajaran example non example di kelas eksperimen berdistribusi normal. Hal ini ditunjukkan dari nilai $X_{\text {hitung }}$ pretest yaitu 0.111 dan nilai $X_{\text {hitung }}$ posttest $0.270<X_{\text {tabel }}$ yaitu 1.695 , maka $\mathrm{H}_{0}$ diterima.

Berdasarkan data yang diperoleh dari nilai pretest dan posttest, maka diperoleh hasil uji homogenitas seperti tabel dibawah ini:

Tabel 2. Rekapitulasi Hasil Perhitungan Uji Homogenitas di Kelas Eksperimen

\begin{tabular}{|c|c|c|c|c|}
\hline Data & Kelas & Fhitung & $\mathrm{F}_{\text {tabel }}$ & Kesimpulan \\
\hline Pretest & $\mathrm{VII}_{9}$ & 0.249 & 1.695 & $\mathrm{H}_{0}$ diterima (Homogen) \\
\hline Posttest & $\mathrm{VII}_{9}$ & 1.121 & 1.695 & Ho diterima (Homogen) \\
\hline
\end{tabular}

Berdasarkan tabel 2 diatas menunjukkan bahwa data nilai pretest dan posttest hasil belajar siswa yang menggunakan model pembelajaran example non example di kelas eksperimen berdistribusi homogen. Hal ini ditunjukkan dari nilai $F_{\text {hitung }}$ pretest yaitu 0.249 dan $F_{\text {hitung }}$ posttest yaitu $1.121<F_{\text {tabel }}$ yaitu 1.695. Artinya bahwa $\mathrm{H}_{0}$ diterima, maka data pretest dan posttes kelas eksperimen bersifat homogen.

Setelah data berdistribusi normal dan homogen, maka dapat dilakukan uji $t$-test dengan teknik paired samples $t$-test. Hasil yang diperoleh dari perhitungan uji $t$ seperti tabel dibawah ini:

Tabel 3. Rekapitulasi Hasil Perhitungan Uji $t$ di Kelas Eksperimen

\begin{tabular}{|c|c|c|c|c|c|}
\hline Data & Kelas & $\mathrm{N}$ & thitung & tabel & Kesimpulan \\
\hline $\begin{array}{c}\text { Pretest dan } \\
\text { posttest }\end{array}$ & VIl9 & 32 & -9.210 & 1.695 & $\begin{array}{c}\mathrm{H}_{0} \text { ditolak } \\
\mathrm{H}_{1} \text { diterima }\end{array}$ \\
\hline
\end{tabular}

Berdasarkan tabel 3 hasil perhitungan uji $t$ yang ditunjukkan pada tabel diatas dengan taraf signifikan $\alpha=0,05$. Dalam hal ini ditunjukkan bahwa nilai dari thitung $=-9.210$ dan tabel $=1.695$, sehingga dalam kasus ini thitung $<$ tabel 
yang berarti $\mathrm{H}_{0}$ ditolak $\mathrm{H}_{1}$ diterima yang artinya terdapat pengaruh example non example terhadap kemampuan berpikir kritis siswa di kelas eksperimen yang signifikan antara nilai pre-test maupun post-test.

Soal pretest terdiri dari 5 butir soal tentang sudut, soal ini diberikan untuk siswa kelas eksperimen yang menggunakan model pembelajaran example non example. Dari hasil nilai pretest kelas eksperimen memiliki nilai rata-rata yaitu 8.56. Dari hasil nilai rata-rata pretest diketahui bahwa kemampuan berpikir kritis siswa masih rendah. Setelah kelas eksperimen siswa diuji dengan pretest, selanjutnya siswa akan diberi materi pembelajaran matematika tentang sudut dengan menggunakan model pembelajaran example non example. Setelah itu, siswa akan diuji lagi dengan posttest sebanyak 5 butir soal untuk mengetahui apakah siswa sudah menguasai materi pembelajaran yang diberikan. Dari hasil posttest diketahui nilai rata-rata siswa yaitu 10.96, hal ini menunjukkan bahwa kemampuan berpikir kritis siswa meningkat setelah diberikan perlakuan (model pembelajaran example non example), dan terdapat perbedaan terhadap nilai rata-rata pretest dan nilai rata-rata posttest.

Berdasarkan pengujian hipotesis menggunakan uji t dengan teknik paired samples $t$-test ditunjukkan bahwa kelas eksperimen pada taraf signifikan $\alpha=0.05$ dalam kasus ini thitung yaitu -9.210 dan tabel $=1.695$, sehingga dalam hal ini thitung lebih kecil dari tabel yang artinya $\mathrm{H}_{0}$ ditolak $\mathrm{H}_{1}$ diterima berarti terdapat pengaruh example non example terhadap kemampuan berpikir kritis siswa di kelas eksperimen yang signifikan antara pretest maupun posttest.

Pola jawaban menunjukkan bahwa 3 siswa dikategorikan berpengetahuan tinggi dengan persentase 9.4 \%, 23 siswa dikategorikan berpengetahuan sedang dengan persentase $71.9 \%$, dan 6 siswa dikategorikan berpengetahuan rendah dengan persentase $18.7 \%$.

\section{Pembahasan Penelitian}

Soal pretest terdiri dari 5 butir soal tentang sudut, soal ini diberikan untuk siswa kelas eksperimen yang menggunakan model pembelajaran example non example. Dari hasil nilai pretest kelas eksperimen memiliki nilai rata-rata yaitu 8.56. Dari hasil nilai rata-rata pretest diketahui bahwa kemampuan berpikir kritis siswa masih rendah. Setelah kelas eksperimen siswa diuji dengan pretest, selanjutnya siswa akan diberi materi pembelajaran matematika tentang sudut dengan menggunakan model pembelajaran example non example. Setelah itu, siswa akan diuji lagi dengan posttest sebanyak 5 butir soal untuk mengetahui apakah siswa sudah menguasai materi pembelajaran yang diberikan. Dari hasil posttest diketahui nilai rata-rata siswa yaitu 10.96, hal ini menunjukkan bahwa kemampuan berpikir kritis siswa meningkat setelah diberikan perlakuan (model pembelajaran example non example), dan terdapat perbedaan terhadap nilai rata-rata pretest dan nilai rata-rata posttest.

Berdasarkan pengujian hipotesis menggunakan uji t dengan teknik paired samples t-test ditunjukkan bahwa kelas eksperimen pada taraf signifikan $\alpha=0.05$ dalam kasus ini thitung yaitu -9.210 dan tabel $=1.695$, sehingga dalam hal ini thitung lebih kecil dari tabel yang artinya $\mathrm{H}_{0}$ ditolak $\mathrm{H}_{1}$ diterima berarti terdapat pengaruh example non example terhadap kemampuan berpikir kritis siswa di kelas eksperimen yang signifikan antara pretest maupun posttest. Pola jawaban menunjukkan bahwa 3 siswa dikategorikan berpengetahuan tinggi dengan persentase $9.4 \%, 23$ siswa dikategorikan berpengetahuan sedang dengan persentase $71.9 \%$, dan 6 siswa dikategorikan berpengetahuan rendah dengan persentase $18.7 \%$.

\section{Kesimpulan}

Berdasarkan hasil penelitian pada siswa kelas VII 9 SMP Negeri I Na. IX-X tahun pembelajaran 2017/2018 dapat disimpulkan bahwa terdapat pengaruh Model Pembelajaran Example Non Example terhadap kemampuan berpikir kritis siswa pada pokok pembahasan"Sudut". Hal ini dapat dibuktikan dari nilai pretest dan posttest siswa yang mana nilai terendah siswa saat pretest adalah 6, setelah diberi perlakuan (treatment) nilai terendah posttest menjadi 8. Nilai tertinggi pretest siswa adalah 10, setelah diberi perlakuan nilai tertinggi posttest adalah 14. Demikian juga berdasarkan uji Paired Samples T-Test diperoleh nilai $-9.120<1.695$ maka Ho ditolak dan $\mathrm{H}_{1}$ diterima, yang berarti semakin sering guru menggunakan model Example Non Example dalam pembelajaran Matematika, maka kemampuan berpikir kritis siswa akan semakin meningkat.

\section{Daftar Pustaka}

[1] Arikunto Suharsimi. 2011. Prosedur Penelitian Suatu Pendekatan Praktik. Jakarta : Rineka Cipta.

[2] Aris Shoimin. 2014. 68 Model Pembelajaran Inovatif dalam Kurikulum 2013. Yogyakarta : Ar-Ruzz Media.

[3] Drs. Daryanto. 2012. Model Pembelajaran Inovatif. Jogjakarta : Gava Media.

[4] Ennis, R.H. 2011. The Nature of Critical Thinking: A Comprehensive Approach. Illinois : University of Illinois.

[5] Hary Kurniadi. 2010. Model Pembelajaran Examples Non Examples.

[6] Endarmoko, Eko. 2007. Tesaurus Bahasa Indonesia. Jakarta: Gramedia Pustaka. 
Jurnal Pembelajaran dan Matematika SIGMA (JPMS)

Vol (No) Month Year

[7] Oemar Hamalik. 2010. Psikologi Belajar Mengajar. Bandung : Sinar Baru Al Gensindo.

[8] Sudjiono Anas. 2008. Pengantar Statistik Pendidikan. Jakarta : Raja Grafindo. 